\title{
Subcutaneous Sarilumab in hospitalised patients with moderate-severe COVID-19 infection compared to the standard of care (SARCOVID): a structured summary of a study protocol for a randomised controlled trial
}

Rosario Garcia-Vicuña ${ }^{1,2,3^{*}}$ (D), Francisco Abad-Santos ${ }^{2,3,4}$, Isidoro González-Alvaro ${ }^{1,3}$, Francisco Ramos-Lima ${ }^{5}$ and Jesús Sanz Sanz ${ }^{3,6}$

\begin{abstract}
Objectives: The main aim of the study is to evaluate the efficacy of a single dose of sarilumab, in subcutaneous administration, in hospitalised patients with moderate to early severe COVID-19 infection compared to the current standard of care, to prevent progression to systemic hyperinflammatory status. Our hypothesis is that use of subcutaneous sarilumab in early stages (window of opportunity) of COVID-19 moderate-severe pneumonia can prevent higher oxygenation requirements through non-invasive and invasive mechanical ventilation and decrease inhospital stays, as well as death rate.

The secondary objectives of the study are to evaluate the safety of sarilumab through hospitalisation and up to day 14 after discharge, compared to the control arm as assessed by incidence of serious and non serious adverse events (SAEs).

In addition, as an exploratory objective, to compare the baseline clinical and biological parameters, including serum IL-6 levels, of the intervention population against controls of the same pandemic outbreak (using a propensity score) to search for markers that identify the best candidates for the treatment with subcutaneous IL-6R inhibitors and to attempt an approximation in the temporal frame of the "window of opportunity"

Trial design: SARCOVID is an investigator-initiated single center randomised proof of concept study.

Participants: Patients treated at the Hospital Universitario La Princesa, Madrid, Spain requiring hospitalisation will be consecutively recruited, meeting all inclusion criteria and none of the exclusion criteria Inclusion criteria

\footnotetext{
* Correspondence: mariadelrosario.garcia@salud.madrid.org

${ }^{1}$ Rheumatology Department, Hospital Universitario de la Princesa, Madrid,

Spain

2Faculty of Medicine, Universidad Autónoma de Madrid (UAM), Madrid, Spain

Full list of author information is available at the end of the article
}

C C The Author(s). 2020 Open Access This article is licensed under a Creative Commons Attribution 4.0 International License, which permits use, sharing, adaptation, distribution and reproduction in any medium or format, as long as you give appropriate credit to the original author(s) and the source, provide a link to the Creative Commons licence, and indicate if changes were made. The images or other third party material in this article are included in the article's Creative Commons licence, unless indicated otherwise in a credit line to the material. If material is not included in the article's Creative Commons licence and your intended use is not permitted by statutory regulation or exceeds the permitted use, you will need to obtain permission directly from the copyright holder. To view a copy of this licence, visit http://creativecommons.org/licenses/by/4.0/. The Creative Commons Public Domain Dedication waiver (http://creativecommons.org/publicdomain/zero/1.0/) applies to the data made available in this article, unless otherwise stated in a credit line to the data. 
(Continued from previous page)

a. Age $>18,<80$ years old

b. COVID-19 infection documented by a positive RT-PCR test or, in absence of a RT-PCR positive test, case definition of COVID 19 infection/pneumonia as per local protocol and the presence of a positive serologic test (lgM/lgA by ELISA)

c. Documented interstitial pneumonia requiring admission and at least two of the following parameters:

1) Fever $\geq 37.8^{\circ} \mathrm{C}$ (tympanic)

2) $\mathrm{IL}-6$ in serum $\geq 25 \mathrm{pg} / \mathrm{mL}$ (in the absence of a previous dose of prednisone or equivalent> $1 \mathrm{mg} / \mathrm{kg}$ ) or PCR> $5 \mathrm{mg} / \mathrm{dL}$

3) Lymphocytes $<600$ cells $/ \mathrm{mm}^{3}$

4) Ferritin $>300 \mu \mathrm{g} / \mathrm{L}$ that doubles in 24 hours

5) Ferritin $>600 \mu \mathrm{g} / \mathrm{L}$ in the first determination and $\mathrm{LDH}>250 \mathrm{U} / \mathrm{L}$

6) D-dimer (> $1 \mathrm{mg} / \mathrm{L})$

d. Informed verbal consent or requested under urgent conditions, documented in the electronic medical record. Exclusion criteria

a. Patients who require mechanical ventilation at the time of inclusion.

b. AST / ALT values > 5 folds the ULN.

c. Absolute neutrophil count below 500 cells $/ \mathrm{mm}^{3}$

d. Absolute platelet count below 50,000 cells $/ \mathrm{mm}^{3}$

e. Documented sepsis or high suspicion of superimposed infection by pathogens other than COVID-19.

f. Presence of comorbidities that can likely lead to an unfavourable result according to clinical judgment.

g. Complicated diverticulitis or intestinal perforation.

h. Current skin infection (eg, uncontrolled dermopiodermitis).

i. Immunosuppressive anti-rejection therapy.

j. Pregnancy or lactation.

k. Previous treatment with tocilizumab or sarilumab.

I. Patients participating in another clinical trial for SARS-CoV-2 infection.

m. Patients with known hypersensitivity or contraindication to sarilumab or excipients.

Intervention and comparator: The intervention group, sarilumab plus standard of care, will receive 400 mg single dose treatment with Sarilumab (Kevzara), 2 subcutaneous injections 200mg each in a pre-filled syringe. Treatment with drugs or procedures in routine clinical practice that the clinician responsible for the patient deems necessary is allowed.

The control group will receive drugs or procedures in routine clinical practice according to the best standard of care as per local protocol.

Main outcomes: Primary Outcome Measures

1. Mean change in clinical status assessment using the 7-point ordinal scale at day 7 after randomisation compared to baseline (Score ranges 1-7)

1. Death;

2. Hospitalised, requiring invasive mechanical ventilation or extracorporeal membrane oxygenation (ECMO);

3. Hospitalised, requiring non-invasive ventilation or high flow oxygen devices;

4. Hospitalised, requiring supplemental oxygen;

5. Hospitalised, not requiring supplemental oxygen - but in need of ongoing medical care (COVID-19 related or otherwise)

6. Hospitalised, not requiring supplemental oxygen - no longer requires ongoing medical care (independent)

7. Not hospitalised

2. Duration of hospitalisation: Days from the date of enrolment to the date of discharge

3. Number of deaths at the end of study

(Continued on next page) 


\section{(Continued from previous page)}

Randomisation: Randomisation to treatment arms sarilumab plus standard of care or standard of care in a 2:1 ratio will be performed by the Clinical Research and Clinical Trials Unit (CRCTU) at the Hospital using a table of random numbers, an internet-based randomisation tool. After checking that all inclusion criteria are met and none of the exclusion criteria, CRCTU will communicate the recruiting investigator the assigned treatment.

Blinding (masking): This study is unblinded.

Numbers to be randomised (sample size): 30 patients treated by COVID-19 infection who require hospitalisation: 20 will receive sarilumab plus Standard of Care and 10 will receive Standard of Care.

Trial Status: The Protocol version number is 2, as of $6^{\text {th }}$ April 2020, with amendment 1, as of $7^{\text {th }}$ May 2020 . The recruitment is ongoing. Recruitment started on April $13^{\text {th }} 2020$ and is anticipated to be completed by November 2020.

Trial registration: This trial was first registered in the European Union Clinical Trials Register on 4 April 2020, EudraCT Number 2020-001634-36. Then, posted on ClinicalTrials.gov on 22 April 2020, Identifier: NCT04357808.

Full protocol: The full protocol is attached as an additional file, accessible from the Trials website (Additional file 1). In the interest in expediting dissemination of this material, the familiar formatting has been eliminated; this Letter serves as a summary of the key elements of the full protocol.

The study protocol has been reported in accordance with the International Council Harmonization guidelines: https://wWw.ich.org/page/efficacy-guidelines.

Keywords: COVID-19, Randomised controlled trial, Open label trial, protocol, SARS-CoV-2, Coronavirus infections, Sarilumab, IL-6 receptor inhibitors

\section{Supplementary information}

Supplementary information accompanies this paper at https://doi.org/10. $1186 /$ s13063-020-04588-5.

Additional file 1. Full Study Protocol.

\section{Acknowledgements}

The authors want to thank Gina Mejía and Elena Santos from the Clinical Research and Clinical trials Unit for their contribution in writing the Pharmacovigilance items in study protocol and helping communication with regulatory authorities, respectively

\section{Authors' contributions}

RGV: Principal investigator, Conceptualization, Methodology design, writing the study protocol and data collection sheet and writing this submission. Obtaining approval for ethics committee and regulatory competent authorities. Fund accounting. FAS: Writing the study protocol and data collection sheet. Obtaining approval for ethics committee and regulatory competent authorities. Editing and review of the English version of the protocol. IGA: Conceptualization, Methodology design. FRL: Translation into English of the Spanish version of the protocol. JSS: Clinical study coordinator and supervision of investigators. The authors read and approved the final protocol and this submission.

\section{Authors' information}

RGV is the Head of the Rheumatology Unit at the Hospital Universitario la Princesa (HUP) and the actual coordinator of the Multidisciplinary Unit of Biologic and Directed Therapies at the Instituto de Investigación Sanitaria La Princesa (IIS-IP). She is assistant professor of Rheumatology at the Universidad Autonoma de Madrid (UAM).

FAS is the Head of Clinical Pharmacology Department at HUP and Coordinator of the Clinical Research and clinical trial Unit (UICEC) of the HUP and IIS-IP. He also is member and promoter of the SCReN Platform (Spanish Clinical Research Network) and Professor in the Pharmacology Department, UAM.

IGA is a Section chief in the Rheumatology Unit at HUP and the leader of its research group in the IIS-IP, as well as the coordinator of the investigational line "Advanced Therapies and personalized Medicine" at the IIS-IP which bring together all activities focused in Biomarkers and personalized medicine.

FRL is Medical Advisor, Medical Affairs Department, Immunology Area at Sanofi Spain with more than 12 years of experience in basic research, before starting in the pharmaceutical industry.

JSS is the chief of the Infectious Diseases division at the Internal Medicine Department and the person in charge of the local protocol for the treatment of COVID-19 infection at HUP.

\section{Funding}

Sanofi provides medication for the intervention arm sarilumab (Kevzara, 40 prefilled syringes). Funds for a data manager are subject to achievement of predefined milestones throughout the study. Sanofi has no role in the design of the study and data collection, analysis, and interpretation of data and in writing the manuscript.

\section{Availability of data and materials}

RGV, FAS and IGA will have access to the final trial dataset. The data will be available from the author on reasonable request. Contact details: Rosario García de Vicuña. mariadelrosario.garcia@salud.madrid.org Rheumatology Unit, Hospital Universitario de la Princesa, IIS-IP, Diego de León 62, 28006, Madrid

Until publication, only research staff have access to the scientific and personal data, in agreement with Regulation (EU) 2016/679, of the European Parliament and of the Council, of 27th April 2016.

\section{Ethics approval and consent to participate}

The Ethics Committee for investigation with medicinal products (CEim) of the Hospital Universitario La Princesa approved the study on March 9th, 2020. The Reference number of the ethical approval judgement is 4075. I certify that this trial has received ethical approval from the appropriate ethical committee as described above. Oral informed consent and request in urgent conditions according to the AEMPS (Spanish Agency for Drugs and Health Products) statement (https://www.aemps.gob.es/informa-en/ exceptional-measures-applicable-to-clinical-trials-to-manage-problems-arisingfrom-the-covid-19-emergency/?lang=en) will be recorded for all participants before enrolling in the study and will be registered in the electronic medical records. 


\section{Consent for publication}

Not applicable.

\section{Competing interests}

RGV declares no competing interests related to the present protocol; She reports she has received educational or research grants from Abbvie, BMS, Janssen Lilly, Novartis, MSD, Roche, and Sanofi; has received personal fees for advisory boards from Abbvie, Biogen, BMS, Celltrion, Mylan, Pfizer, Roche, Sandoz and Sanofi; has delivered presentations sponsored by BMS, Lilly, Pfizer, Sandoz and Sanofi; has received non-financial support for Abbvie, BMS, Lilly, MSD, Novartis, Pfizer and Sanofi, all outside the submitted work. FAS declares he has no competing interests.

FRL is Medical Advisor at Sanofi Spain. He declares no competing interests related to the present protocol.

IGA declares no competing interests related to the present protocol. He reports grants from ISCIII, grants from Fundación La Caixa; personal fees from Lilly, personal fees and non-financial support from BMS, personal fees from Sanofi, personal fees and non-financial support from Abbvie, grants, personal fees and non-financial support from Roche, non-financial support from MSD, non-financial support from Pfizer, non-financial support from Novartis, outside the submitted work;

JSS declares he has no competing interests.

\section{Author details}

${ }^{1}$ Rheumatology Department, Hospital Universitario de la Princesa, Madrid, Spain. ${ }^{2}$ Faculty of Medicine, Universidad Autónoma de Madrid (UAM), Madrid, Spain. Instituto de Investigación Sanitaria La Princesa (IIS-IP), Madrid, Spain. ${ }^{4}$ Clinical Pharmacology Department, Unidad de Investigación Clínica y Ensayos Clínicos (UICEC), Hospital Universitario de la Princesa, Plataforma SCReN (Spanish Clinical Research Network), Madrid, Spain. ${ }^{5}$ Medical Affairs Department, Immunology Area, Sanofi Spain, Madrid, Spain. ${ }^{6}$ Division of Infectious Diseases, Internal Medicine Department, Hospital Universitario de la Princesa, Madrid, Spain.

Received: 1 July 2020 Accepted: 7 July 2020

Published online: 09 September 2020

\section{Publisher's Note}

Springer Nature remains neutral with regard to jurisdictional claims in published maps and institutional affiliations.

Ready to submit your research? Choose BMC and benefit from:
- fast, convenient online submission
- thorough peer review by experienced researchers in your field
- rapid publication on acceptance
- support for research data, including large and complex data types
- gold Open Access which fosters wider collaboration and increased citations
- maximum visibility for your research: over 100M website views per year
At BMC, research is always in progress.
Learn more biomedcentral.com/submissions

